\title{
Fluxo portal e visceral líquido de metabólitos em ovinos alimentados com feno de capim-arroz cortado com diferentes idades de rebrota
}

\author{
Gilberto Vilmar Kozloski ${ }^{1}$, Lisiane Dorneles de Lima ${ }^{2}$, Andréa Paola Ruggia Chiesa ${ }^{2}$, \\ Lisandre de Oliveira $^{3}$, Giovani Fiorentini ${ }^{3}$, Carla Joice Härter ${ }^{3}$
}

\footnotetext{
${ }^{1}$ Departamento de Zootecnia - Universidade Federal de Santa Maria (UFSM)

2 Mestrando em Zootecnia - UFSM.

${ }^{3}$ Curso de Graduação - Bolsista de Iniciação Científica - UFSM.
}

RESUMO - Foram conduzidos dois ensaios para medir os fluxos portal e visceral total de metabólitos em ovinos (peso vivo (PV) médio de $35 \pm 3 \mathrm{~kg}$ ) recebendo feno de capim-arroz (Echinochloa sp.) cortado aos 32, 46, 72 ou 90 dias de rebrota. Um dos ensaios foi realizado em quadrado latino $4 \times 4$ (ensaio 1) para avaliação dos quatro fenos e outro em quadrado latino $3 \times 3$ (ensaio 2), sem o feno do capim cortado aos 32 dias de rebrota. Os animais foram implantados com cateteres permanentes nas veias mesentérica e hepática. Sangue arterial foi acessado através de cateteres temporários na carótida. O fluxo de sangue portal e visceral foi estimado com base na diluição de paraminohipurato infundido continuamente em uma veia mesentérica $\mathrm{Na}$ refeição prévia às amostragens, o consumo de matéria orgânica (MO) total e digestível não foi afetado, mas o consumo de nitrogênio total e digestível diminuiu linearmente com o aumento da idade de rebrota do capim-arroz em ambos os ensaios Os fluxos de sangue portal e visceral, o fluxo visceral líquido de glicose, uréia e aminoácidos e o fluxo portal líquido de glicose e uréia não foram afetados pela idade de rebrota da forrageira. Os fluxos portais de aminoácidos e amônia foram maiores nos animais que consumiram o feno de 46 dias e maior quantidade de nitrogênio digestível. A maior parte dos nutrientes absorvidos pelos ovinos consumindo feno de capim-arroz foi metabolizada pelo sistema visceral, de modo que a disponibilidade de aminoácidos e de glicose aos tecidos periféricos representou somente pequena proporção do nitrogênio ou da matéria orgânica ingerida. Em geral, o metabolismo visceral dos animais não foi afetado pela idade de rebrota da forrageira.

Palavras-chave: aminoácidos, amônia, Echinochloa sp., glicose, metabolismo, uréia

\section{Net portal and visceral flux of metabolites in lambs fed rice-grass hay cut at different regrowth ages}

\begin{abstract}
In order to measure the net portal and visceral flux of metabolites in lambs $(35 \pm 2.5 \mathrm{~kg}$ live weight) fed rice-grass (Echinochloa sp.) hay cut at 32, 46, 72 or 96 days of regrowth age, two assays were carried out. One of them was a $4 \times 4$ Latin Square experiment (Assay 1) where the four hays were evaluated and the other was a $3 \times 3$ Latin square experiment (Assay 2) that did not include the 32-day hay. Animals were surgically implanted with permanent catheters into mesenteric and hepatic blood vessels. Arterial blood was sampled using temporary catheters into carotid artery. Portal and visceral blood flow was estimated based on continuous infusion of paraminohippurate in a mesenteric vein. On the sampling day, total and digestible organic matter (OM) intakes were not affected, but total and digestible $\mathrm{N}$ intakes decreased linearly with the increased forage regrowth age in both assays. The portal and visceral blood flow, net visceral flux of glucose, urea and amino acids and the net portal flux of glucose and urea were not affected by forage regrowth age. The net portal flux of amino acids and ammonia which was markedly higher in lambs fed 46-day hay and that ingested more digestible $\mathrm{N}$ Most nutrients absorbed by lambs fed rice-grass hay were metabolized by visceral tissues such as peripheral availability of amino acids and glucose only account to a small proportion of $\mathrm{N}$ and $\mathrm{OM}$ intake. In general, the visceral metabolism of lambs is not clearly affected by forage regrowth age.
\end{abstract}

Key Words: amino acids, ammonia, Echinochloa sp., glucose, metabolism, urea

\section{Introdução}

O desempenho dos ruminantes é altamente dependente do consumo de matéria orgânica (MO) digestível e da eficiência como os nutrientes absorvidos são utilizados pelos animais. No entanto, a regulação da disponibilidade de nutrientes para os tecidos periféricos é afetada pelo metabolismo visceral. O sistema visceral é representado pelos tecidos drenados pela veia porta (trato gastrintestinal, gordura mesentérica, pâncreas e baço) mais o fígado. 
Vários estudos têm comprovado que grande parte da variação na eficiência de utilização da energia metabolizável entre os alimentos está associada ao metabolismo nesses tecidos (Huntington \& Reynolds, 1987; McBride \& Kelly, 1990; Goetsch, 1998), por isso, uma proporção significativa dos aminoácidos absorvidos pode ser utilizada pelos tecidos viscerais e, o nitrogênio $(\mathrm{N})$ desses aminoácidos, metabolizado no fígado a uréia. Estudos desta natureza, contudo, são raros com animais alimentados com forrageiras tropicais. Além disso, apesar de relativamente bem estabelecido que, com o avanço da maturidade da forragem, geralmente ocorre redução do consumo, da digestibilidade e da oferta de nutrientes ao animal (Nelson \& Moser, 1994), pouco se sabe sobre o efeito da idade de rebrota das gramíneas tropicais sobre o metabolismo do sistema visceral.

Com base nessas informações, foram conduzidos dois ensaios para medir os fluxos portal e visceral total de alguns metabólitos em ovinos recebendo feno de capim-arroz de diferentes idades de rebrota.

\section{Material e Métodos}

Foram conduzidos dois ensaios com ovinos Ideal Texel (peso vivo (PV) médio de $35 \pm 3 \mathrm{~kg}$ ) para medir os fluxos portal e visceral total de metabólitos em ovinos recebendo feno de capim-arroz (Echinochloa sp.) cortado aos 32, 46, 72 e 90 dias de rebrota. Um dos ensaios foi realizado em quadrado latino $4 \times 4$ (ensaio 1) para avaliação dos quatro fenos e o outro, em quadrado latino $3 \times 3$ (ensaio 2 ), sem o feno do capim cortado aos 32 dias de rebrota. Durante o ensaio 2, um dos animais perdeu a patência do cateter portal e outro, do cateter hepático. Por isso, foram incluídos animais adicionais para completar o quadrado latino, de modo que neste ensaio a medida do fluxo visceral não foi feita no mesmo grupo de animais em que foi medido o fluxo portal de metabólitos.

Todos os animais foram mantidos confinados em gaiolas metabólicas, no interior de um galpão de alvenaria coberto. As dietas experimentais foram constituídas de feno picado (partículas de 10-15 cm) fornecido duas vezes ao dia (às $8 \mathrm{~h}$ e às $17 \mathrm{~h}$ ), em quantidades suficientes para que as sobras correspondessem de 10 a $20 \%$ do oferecido.

Os cateteres foram implantados cirurgicamente nos animais, sob anestesia geral, nas veias porta, hepática e mesentérica, de acordo com método adaptado de Katz \& Bergman (1969). Para acessar o sangue arterial, uma das carótidas foi elevada cirurgicamente à região subcutânea do pescoço. A descrição detalhada da preparação dos cateteres e das cirurgias foi realizada previamente por Kozloski et al. (2008). Durante o experimento, os cateteres foram mantidos perfundidos com solução salina contendo $200 \mathrm{UI} / \mathrm{mL}$ de heparina, $8 \mathrm{mg} / \mathrm{mL}$ de ampicilina e $10 \mathrm{ul} / \mathrm{mL}$ de etanol, aplicada a cada três dias. Externamente, os cateteres foram protegidos com tiras largas de esparadrapo aderidas à pele com adesivo comercial.

Durante aproximadamente três semanas antes e duas semanas após as cirurgias, os animais foram mantidos em adaptação às instalações e em recuperação das cirurgias, recebendo feno de capim-arroz (mistura de todas as idades disponíveis). Em seguida, os ensaios foram conduzidos em quatro (ensaio 1) e três (ensaio 2) períodos de oito dias, respectivamente: os primeiros sete dias para adaptação aos fenos e o último dia para coleta de amostras.

Na manhã do oitavo dia de cada período experimental, foi implantado um cateter (18 gauges, 1,3 $\mathrm{mm}$ d.e. e $4,8 \mathrm{~cm}$ comprimento, Becton Dickinson, Minas Gerais, Brasil) temporário na carótida, acoplado a uma extensão com uma torneira de três vias. $\mathrm{O}$ feno foi então oferecido e mantido disponível aos animais durante 60 minutos. Sequencialmente, as sobras foram retiradas, pesadas, e o fluxo portal e visceral de sangue foi medido pela aplicação na veia mesentérica de uma dose inicial de $10 \mathrm{~mL}$ (primed), seguida de infusão contínua ( $1 \mathrm{~mL} /$ minuto) de uma solução de paraminohipurato $(\mathrm{PAH})$ a 1,5 \% (p/v), pH 7,4, com auxílio de uma bomba peristáltica. Após 30 minutos do início da infusão do indicador, oito amostras simultâneas de sangue arterial, hepático e/ou portal foram coletadas em seringas heparinizadas a intervalos de uma hora. Entre os intervalos de amostragem, os catéteres foram mantidos heparinizados com solução fisiológica contendo $20 \mathrm{UI} / \mathrm{mL}$ de heparina. Imediatamente após a coleta, as amostras de sangue foram colocadas em tubos contendo $\mathrm{NaF}$ (em torno de $1,5 \mathrm{mg} / \mathrm{mL}$ sangue) e mantidas em gelo. O volume celular (microcentrífuga Centimicro Mod. 211, FANEM, SP, Brasil) foi medido, o restante do sangue foi centrifugado $(1000 \times g$, 20 minutos) e o plasma foi congelado para posterior análise.

Amostras do feno oferecido e das sobras foram coletadas, secas a aproximadamente $55^{\circ} \mathrm{C}$ durante pelo menos 72 horas, moídas (peneira com porosidade de $1 \mathrm{~mm}$ ) e armazenadas para posterior análise (Tabela 1). O teor de matéria seca (MS) foi determinado por secagem em estufa a $105^{\circ} \mathrm{C}$ durante pelo menos 8 horas e as cinzas, por queima em mufla a $550^{\circ} \mathrm{C}$ durante 3 horas. $\mathrm{O}$ teor de nitrogênio total foi determinado pelo método Kjeldahl (método 984.13, AOAC, 1995), modificado conforme descrito por Kozloski et al. (2003). O teor de fibra em detergente neutro (FDN) foi determinado, sem uso de sulfito de sódio e alfa-amilase, conforme Mertens (2002), porém as amostras foram pesadas em sacos de poliéster (Komarek, 1993) e tratadas com detergente neutro em autoclave a $120^{\circ} \mathrm{C}$ durante 1 hora. Os 
Tabela 1 - Composição química do feno de capim-arroz em diferentes idades de rebrota

\begin{tabular}{lcccc}
\hline & \multicolumn{4}{c}{ Idade de rebrota (dias) } \\
\cline { 2 - 5 } & 32 & 46 & 72 & 90 \\
\hline Matéria seca (MS, \%) & 86,3 & 86,6 & 85,3 & 85,9 \\
& \multicolumn{4}{c}{$\%$ MS } \\
Matéria orgânica & 90,3 & 90,2 & 90,2 & 90,2 \\
Fibra em detergente neutro & 70,0 & 71,4 & 70,3 & 71,9 \\
Fibra em detergente ácido & 35,1 & 35,0 & 37,9 & 39,4 \\
Lignina & 4,46 & 5,32 & 5,56 & 6,54 \\
Extrato etéreo & 1,61 & 1,18 & 1,05 & 1,20 \\
Carboidratos não-fibrosos & 9,1 & 9,8 & 10,7 & 10,7 \\
Nitrogênio total & 1,67 & 1,34 & 1,44 & 1,11 \\
\hline
\end{tabular}

teores de fibra em detergente ácido (FDA) e lignina em detergente ácido (LDA) foram determinados de acordo com AOAC (método 973.18, AOAC, 1995), mas sem uso de amianto. O teor de gordura foi determinado por extração com éter etílico em sistema de refluxo a $180^{\circ} \mathrm{C}$ durante 3 horas.

Nas amostras de plasma, foram determinadas as concentrações de glicose (método glicose-oxidase) e uréia (método urease-indofenol) utilizando-se kits comerciais (LABTEST, MG, Brasil). Foram analisadas também as concentrações de PAH (Huntington, 1982), aminoácidos (Palmer \& Peters, 1969) e amônia (Weatherburn, 1967). Para determinação de glicose e uréia, o plasma foi previamente diluído cinco vezes com água destilada. Para determinação de PAH, aminoácidos e amônia, o plasma foi previamente precipitado com mesmo volume de uma solução de ácido tricloroacético a $10 \%(\mathrm{p} / \mathrm{v})$

O fluxo de sangue portal (FSP) ou visceral (FSV) foi estimado usando a seguinte fórmula:

FSP ou FSV $($ litros/hora $)=$ GIpah $/(\mathrm{P}$ ou $\mathrm{H}-\mathrm{A})$, em que: GIpah = grau de infusão do PAH $(\mathrm{mg} / \mathrm{h})$; $\mathrm{P}=$ concentração de PAH no sangue portal ( $\mathrm{mg} / \mathrm{litro})$; $\mathrm{H}=$ concentração de PAH no sangue hepático ( $\mathrm{mg} /$ litro); $\mathrm{A}=$ concentração de PAH no sangue arterial ( $\mathrm{mg} / \mathrm{litro})$.

O fluxo líquido de metabólitos foi calculado como a diferença entre a concentração venosa menos a arterial do metabólito multiplicada pelo fluxo de sangue portal ou visceral.

Provavelmente em razão da mistura inadequada do PAH no sangue, os resultados de fluxo de sangue portal dos animais no ensaio 1 foram muito variáveis e, por isso, foram excluídos da análise. Na análise de dados de metabolismo portal, foram incluídos somente os resultados obtidos no ensaio 2. Os dados de fluxo visceral total dos ensaios 1 e 2, por sua vez, foram analisados conjuntamente.

A variância dos dados foi analisada pelo PROC MIXED do SAS (2002), de acordo com o seguinte modelo:
$\mathrm{Y}_{\mathrm{ijkl}}=\mu+\mathrm{A}_{\mathrm{i}}+\mathrm{P}_{\mathrm{j}}+\mathrm{D}_{\mathrm{k}}+\mathrm{A}(\mathrm{P} \times \mathrm{D})_{\mathrm{ijk}}+\mathrm{T}_{1}+(\mathrm{D} \times \mathrm{T})_{\mathrm{kl}}+\mathrm{e}_{\mathrm{ijkl}}$ em que: A, P, D representam os efeitos de animais, períodos e dieta, de modo que $\mathrm{T}=0$ tempo; $\mathrm{D} \times \mathrm{T}=$ efeito da interação dieta e tempo; $\mathrm{A}(\mathrm{P} \times \mathrm{D})=$ efeito aleatório de unidades experimentais; $\mu=$ média das observações; e $\mathrm{e}_{\mathrm{ijkl}}=$ erro residual.

$O$ efeito da idade de rebrota foi analisado por regressão utilizando-se o PROC GLM do programa estatístico SAS (2002). Quando conveniente, as médias também foram comparadas pelo teste Tukey a $5 \%$ de probabilidade do erro tipo I.

\section{Resultados e Discussão}

$\mathrm{Na}$ refeição prévia às amostragens, o consumo de matéria orgânica total e digestível não foi afetado, mas o de nitrogênio total e digestível diminuiu linearmente $(\mathrm{P}<0,05)$ com a idade de rebrota do capim-arroz em ambos os ensaios (Tabelas 2 e 3 ).

Não houve interação $(\mathrm{P}>0,05)$ entre idades de rebrota e tempo após a alimentação em nenhuma das variáveis analisadas. Pela análise de regressão, não foi observada variação regular $(\mathrm{P}>0,05)$ nas concentrações sanguíneas ou no fluxo portal e visceral dos metabólitos após a alimentação (Tabelas 4 e 5). Não existe um método padrão para medir fluxo de sangue que permita avaliar o grau de exatidão dos resultados experimentais. No entanto, os resultados de fluxo de sangue portal (média de 2 litros/kg de PV ou 5 litros/ $\mathrm{kg}$ de $\mathrm{PV}^{0,75}$ ) e visceral (média de 2,4 litros/kg de PV ou 5,9 litros $/ \mathrm{kg}$ de $\mathrm{PV}^{0,75}$ ) obtidos neste estudo são similares aos reportados em outros estudos com ovinos (Ortigues et al., 1994; Milano et al., 2000; Branco et al., 2004; Sole et al., 2004; Mouro et al., 2006; Mouro et al., 2007). O fluxo de sangue pelo sistema visceral normalmente é diretamente relacionado ao consumo de alimento (Reynolds et al., 1991). De fato, nos animais em que foi medido o metabolismo portal, nem o consumo de matéria orgânica nem o fluxo de sangue portal foi afetado $(\mathrm{P}>0,05)$, mas, naqueles em que foi medido o metabolismo visceral, embora o consumo de matéria orgânica tenha sido similar entre os tratamentos, o fluxo de sangue visceral diminuiu linearmente com o aumento da idade de rebrota do capim-arroz $(\mathrm{P}<0,05)$. Nesse ensaio, foi considerado somente o consumo prévio à coleta de amostras de sangue. É possível então que, diferente do portal, o fluxo de sangue visceral seja afetado e dependa do consumo de vários dias e não à quantidade consumida em uma refeição isoladamente.

Nos animais em que foi medido o metabolismo portal, as concentrações arteriais e portais de glicose, aminoácidos, uréia e amônia diminuíram linearmente $(\mathrm{P}<0,05)$ com o aumento da idade de rebrota do capim-arroz. Esse mesmo 
Tabela 2 - Consumo (g) de matéria orgânica e nitrogênio durante a refeição da manhã por ovinos alimentados com feno de capim-arroz cortado com diferentes idades de rebrota (médias dos ensaios 1 e 2)

\begin{tabular}{|c|c|c|c|c|c|c|}
\hline & \multicolumn{4}{|c|}{ Idade de rebrota (dias) } & Desvio-padrão ${ }^{2}$ & $\mathrm{P}^{3}$ \\
\hline Matéria orgânica (MO) & 198 & 222 & 183 & 216 & 44 & $\mathrm{~ns}$ \\
\hline MO aparentemente digestível ${ }^{1}$ & 108 & 120 & 102 & 102 & 23 & ns \\
\hline MO verdadeiramente digestível ${ }^{1}$ & 149 & 162 & 135 & 147 & 22 & ns \\
\hline $\mathrm{N}$ aparentemente digestível ${ }^{1}$ & 1,8 & 1,4 & 1,5 & 0,9 & 0,2 & * \\
\hline
\end{tabular}

${ }^{1}$ Estimados com base em um ensaio prévio de digestibilidade com ovinos recebendo os diferentes fenos de capim-arroz (Lima, 2007).

${ }^{2}$ Desvio-padrão das médias: $\mathrm{n}=7$ por tratamento, exceto no tratamento 32 dias, de modo que $\mathrm{n}=4$.

${ }^{3}$ Probabilidade do efeito linear da análise de regressão (erro tipo I): ns = não-significativo; * $\mathrm{P}<0.05$.

Tabela 3 - Consumo (g) de matéria orgânica e nitrogênio durante a refeição da manhã por ovinos alimentados com feno de capim-arroz cortado com diferentes idades de rebrota (médias do ensaio 2)

\begin{tabular}{|c|c|c|c|c|c|}
\hline & \multicolumn{4}{|c|}{ Idade de rebrota (dias) } & $\mathrm{P}^{3}$ \\
\hline Matéria orgânica (MO) & 274 & 192 & 221 & 29 & ns \\
\hline MO aparentemente digestível ${ }^{1}$ & 156 & 114 & 113 & 16 & ns \\
\hline MO verdadeiramente digestível ${ }^{1}$ & 200 & 142 & 151 & 20 & ns \\
\hline $\mathrm{N}$ aparentemente digestível ${ }^{1}$ & 1,8 & 1,7 & 0,9 & 0,2 & $*$ \\
\hline
\end{tabular}

${ }^{1}$ Estimados com base em um ensaio prévio de digestibilidade com ovinos recebendo os diferentes fenos de capim-arroz (Lima, 2007).

2 Desvio-padrão das médias: $\mathrm{n}=3$ animais por tratamento.

${ }^{3}$ Probabilidade do efeito linear da análise de regressão (erro tipo I) : ns = não-significativo; * $\mathrm{P}<0,05$.

efeito foi observado nas concentrações sanguíneas de glicose, uréia e aminoácidos nos animais em que foi medido o metabolismo visceral. Neste último caso, no entanto, o feno de 32 dias estava incluído entre os tratamentos e as concentrações arteriais e venosas de aminoácidos nestes animais variaram de forma quadrática ( $\mathrm{P}<0,05)$, de modo que as concentrações mais altas desses metabólitos foram observadas nos animais que receberam o feno de 46 dias. A explicação e relevância deste efeito, contudo, não são conhecidas. O metabolismo e as concentrações sanguíneas dos nutrientes são resultado da interação de vários fatores associados à oferta de energia metabolizável e de cada nutriente individualmente, à condição fisiológica do animal e ao tempo após a refeição, entre outros. A oferta do feno de 32 dias de rebrota resultou em consumo mais alto de nitrogênio. No entanto, o consumo de matéria orgânica digestível tendeu a ser mais alto entre os animais que receberam o feno de 46 dias. É possível que o consumo de matéria orgânica digestível tenha sido mais determinante das concentrações sanguíneas de aminoácidos que o consumo de nitrogênio. Os valores médios das concentrações sanguíneas dos metabólitos avaliados neste estudo são fisiologicamente normais e similares aos obtidos em outros estudos com ovinos (Goetsch et al., 1997; Milano et al., 2000; Sole et al., 2004; Branco et al., 2004; Mouro et al., 2006; Mouro et al., 2007).

Embora as concentrações sanguíneas tenham sido claramente afetadas, não foi observado efeito $(\mathrm{P}>0,05)$ da idade de rebrota da forrageira sobre o fluxo visceral líquido de nenhum dos metabólitos analisados, tampouco sobre o fluxo portal líquido de glicose e uréia. Os fluxos portais de aminoácidos e amônia diminuíram linearmente com a idade de rebrota do capim-arroz $(\mathrm{P}<0,05)$. Quando comparadas pelo teste de Tukey (resultado não apresentado), no entanto, as médias destas variáveis foram significativamente mais altas nos animais consumindo o feno de 46 dias de rebrota, e similar entre os demais. Como esperado, esse efeito foi diretamente relacionado ao consumo de nitrogênio digestível pelos animais recebendo os tipos de feno. Os fluxos portais e viscerais absolutos de metabólitos foram relativamente menores que os verificados em outros estudos em que os ovinos receberam dietas contendo altos níveis de concentrado e apresentaram maior nível de consumo (Branco et al., 2004; Mouro et al., 2006; Mouro et al., 2007), mas foram similares aos obtidos com ovinos alimentados exclusivamente com feno de gramíneas forrageiras tropicais ou temperadas (Goetsch et al., 1997). 
Tabela 4 - Fluxo de sangue portal, concentração sanguínea e fluxo portal líquido de metabólitos em ovinos alimentados com feno de capim arroz cortado com diferentes idades de rebrota

\begin{tabular}{|c|c|c|c|c|c|}
\hline & \multicolumn{3}{|c|}{ Idade de rebrota (dias) } & Desvio-padrão ${ }^{1}$ & $\mathrm{P}^{2}$ \\
\hline Fluxo de sangue portal $(\mathrm{L} / \mathrm{h})$ & 70 & 74 & 72 & 6 & ns \\
\hline \multicolumn{6}{|l|}{ Concentração arterial (mM) } \\
\hline $\begin{array}{l}\text { Glicose } \\
\mathrm{N} \alpha \text {-amino } \\
\mathrm{N} \text { uréia } \\
\mathrm{N} \text { amônia }\end{array}$ & $\begin{array}{l}2,58 \\
3,75 \\
6,40 \\
0,41 \\
\end{array}$ & $\begin{array}{l}2,53 \\
4,06 \\
7,10 \\
0,36 \\
\end{array}$ & $\begin{array}{l}2,42 \\
3,28 \\
5,63 \\
0,34\end{array}$ & $\begin{array}{l}0,20 \\
0,30 \\
0,37 \\
0,05\end{array}$ & $\begin{array}{l}* \\
* \\
* \\
*\end{array}$ \\
\hline \multicolumn{6}{|l|}{ Concentração portal (mM) } \\
\hline $\begin{array}{l}\text { Glicose } \\
\mathrm{N} \alpha \text {-amino } \\
\mathrm{N} \text { uréia } \\
\mathrm{N} \text { amônia }\end{array}$ & $\begin{array}{l}2,60 \\
4,13 \\
6,33 \\
0,69\end{array}$ & $\begin{array}{l}2,53 \\
4,08 \\
6,87 \\
0,44\end{array}$ & $\begin{array}{l}2,39 \\
3,30 \\
5,50 \\
0,44\end{array}$ & $\begin{array}{l}0,20 \\
0,30 \\
0,43 \\
0,08\end{array}$ & $\begin{array}{l}* \\
* \\
* \\
*\end{array}$ \\
\hline
\end{tabular}

${ }^{1}$ Desvio-padrão das médias, em que $\mathrm{n}=24$ por tratamento.

2 Probabilidade do efeito linear da análise de regressão (erro Tipo I) : ns = não-significativo; * $\mathrm{P}<0,05$.

${ }^{3}$ Serina foi utilizada como padrão.

Tabela 5 - Fluxo de sangue visceral, concentração sanguínea e fluxo visceral líquido de metabólitos em ovinos alimentados com feno de capim-arroz cortado em diferentes idades de rebrota

\begin{tabular}{|c|c|c|c|c|c|c|c|}
\hline & \multicolumn{4}{|c|}{ Idade de rebrota (dias) } & \multirow[b]{2}{*}{$\mathrm{DP}^{1}$} & \multicolumn{2}{|c|}{$\mathrm{P}^{2}$} \\
\hline & 32 & 46 & 72 & 90 & & Linear & Quadrático \\
\hline Fluxo de sangue visceral (litros/hora) & 95 & 83 & 81 & 79 & 13 & * & ns \\
\hline \multicolumn{8}{|l|}{ Concentração arterial (mM) } \\
\hline $\begin{array}{l}\text { Glicose } \\
\mathrm{N} \alpha \text {-amino } \\
\mathrm{N} \text { uréia }\end{array}$ & $\begin{array}{l}3,29 \\
2,50 \\
8,50\end{array}$ & $\begin{array}{l}2,66 \\
2,90 \\
6,70\end{array}$ & $\begin{array}{l}2,63 \\
2,69 \\
6,83\end{array}$ & $\begin{array}{l}2,67 \\
2,37 \\
6,30\end{array}$ & $\begin{array}{l}0,17 \\
0,25 \\
0,53\end{array}$ & $\begin{array}{l}* \\
* \\
*\end{array}$ & $\begin{array}{l}\mathrm{ns} \\
* \\
\mathrm{~ns}\end{array}$ \\
\hline \multicolumn{8}{|l|}{ Concentração no sangue hepático (mM) } \\
\hline $\begin{array}{l}\text { Glicose } \\
\mathrm{N} \alpha \text {-amino } \\
\mathrm{N} \text { uréia }\end{array}$ & $\begin{array}{l}3,40 \\
2,55 \\
8,57 \\
\end{array}$ & $\begin{array}{l}2,83 \\
2,78 \\
6,90\end{array}$ & $\begin{array}{l}2,74 \\
2,64 \\
7,00 \\
\end{array}$ & $\begin{array}{l}2,72 \\
2,38 \\
6,67 \\
\end{array}$ & $\begin{array}{l}0,19 \\
0,35 \\
0,67\end{array}$ & $\begin{array}{l}* \\
* \\
*\end{array}$ & $\begin{array}{c}\mathrm{ns} \\
* \\
\mathrm{~ns}\end{array}$ \\
\hline \multicolumn{8}{|l|}{ Fluxo visceral líquido (mM/hora) } \\
\hline
\end{tabular}

${ }^{1}$ Desvio-padrão das médias: $\mathrm{n}=56$ por tratamento, exceto no feno de 32 dias, no qual $\mathrm{n}=32$.

2 Probabilidade do efeito linear (L) ou quadrático (Q) da análise de regressão (erro Tipo I) : ns = não-significativo; * $\mathrm{P}<0,05$.

${ }^{3}$ Serina foi utilizada como padrão.

Ao longo das 8 horas de amostragem, o fluxo portal de nitrogênio na forma de amônia variou de 0,56 a 2,08 g, que representa de 19 a $54 \%$, enquanto, na forma de $\alpha$-amino, variou de 0,2 a 3, $0 \mathrm{~g}$, representando 6 a 79\% do N verdadeiramente digestível consumido na refeição da manhã. Por sua vez, o fluxo visceral de $\mathrm{N}$ na forma de aminoácidos variou de 0,09 a $0,53 \mathrm{~g}$, representando somente 3 a $18 \%$ e, na forma de uréia, variou de 1,76 a 2,38 g, que corresponde de 59 a $108 \%$ do consumo de $\mathrm{N}$ verdadeiramente digestível. Esses resultados indicam que somente pequena fração do $\mathrm{N}$ absorvido ficou disponível aos tecidos periféricos como aminoácidos. A maior parte do nitrogênio absorvido, independentemente se na forma de amônia ou de aminoácidos, foi metabolizada no fígado a uréia. 
Em animais consumindo forragem, a maior parte dos carboidratos digestíveis da dieta é fermentada no rúmen a ácidos graxos voláteis e, desse modo, a absorção de glicose é nula e seu fluxo portal geralmente negativo (Huntington, 1999). Assim, a neoglicogênese hepática, principalmente a partir de propionato e aminoácidos neoglicogênicos, é fonte primordial deste metabólito para os tecidos periféricos. O fluxo visceral líquido de glicose é resultado da glicose produzida pelo fígado menos a glicose sanguínea utilizada pelo sistema portal. A maior parte do sistema portal é representada pelo trato gastrintestinal, o qual chega a utilizar em torno de até $50 \%$ da glicose total disponível no organismo, seja de origem hepática ou dietética (El-Kadi et al., 2003). Neste estudo, ao longo das oito horas de amostragem, o fluxo visceral de glicose representou somente em torno de $8 \%$ do consumo de MO verdadeiramente digestível durante a refeição da manhã.

Como na maioria dos estudos similares presentes na literatura, o grau de variação dos resultados de concentração sanguínea foi baixo, mas o fluxo portal e visceral dos metabólitos foi relativamente alto. Isso é resultado do metabolismo dos tecidos, o qual é dinâmico e influenciado por vários fatores, como pela condição fisisiológica do animal, pelo tipo e qualidade da dieta, nível de consumo e tempo após a refeição (Huntington, 1999). Na maior parte dos estudos presentes na literatura, o fluxo portal e visceral de metabólitos é relacionado ao consumo médio diário de alimento nos dias prévios ao da amostragem, enquanto neste estudo foi considerado o consumo de feno somente da refeição da manhã. De fato, é provável que o fluxo e metabolismo da glicose, uréia, amônia e aminoácidos seja resultado da interação do consumo de vários dias e da refeição prévia à amostragem. Além disso, pequenas diferenças nas concentrações artério-venosas de qualquer metabólito, quando multiplicadas pelo fluxo sanguíneo, resultam em relativamente grandes variações no fluxo líquido de metabólitos (Bergman, 1975).

Para melhorar a precisão de estudos desta natureza, é necessário, entre outros, aumentar a frequência de oferta de alimento durante o período experimental e o número de observações em cada animal ao longo de um dia de amostragem (Huntington, 1999). O aumento da freqüência da oferta do alimento, em intervalos regulares de tempo, pode ser viabilizado pelo uso de dietas peletizadas distribuídas aos animais com alimentadores automáticos ou por uso intensivo de mão-de-obra durante o estudo. No entanto, além da dificuldade prática de viabilizar qualquer uma destas alternativas, os resultados obtidos não irão representar as variações do metabolismo pós-prandial normalmente existente nos sistemas de produção de ruminantes. O aumento do número de amostragens em cada animal-período, por sua vez, deve ser feito considerando a quantidade total de sangue possível de ser extraída dos animais em cada período, a qual não deve comprometer a volemia nem exceder a capacidade de reposição das células sanguíneas dos animais.

\section{Conclusões}

A maior parte dos nutrientes absorvidos pelos ovinos consumindo feno de capim-arroz foi metabolizada pelo sistema visceral, de modo que a disponibilidade de aminoácidos e de glicose aos tecidos periféricos representou somente pequena proporção do nitrogênio ou da matéria orgânica ingerida. O metabolismo visceral dos animais não foi significativamente afetado pela idade de rebrota da forrageira.

\section{Literatura Citada}

ASSOCIATION OF OFFICIAL ANALYTICAL CHEMISTS - AOAC. Official methods of analysis. 16.ed. Washington, D.C.: AOAC International, 1995. 1094p.

BERGMAN, E.N. Production and utilization of metabolites by the alimentary tract as measured in portal and hepatic blood. In: INTERNATIONAL SYMPOSIUM ON RUMINANT PHYSIOLOGY, 1975, Armidale. Proceedings... Armidale: University of New England, 1975. p.292-395.

BRANCO, A.F.; MOURO, G.F.; HARMON, D.L. et al. Fontes de proteína, ingestão de alimentos e fluxo esplâncnico de nutrientes em ovinos Revista Brasileira de Zootecnia, v.33, p.444$452,2004$.

EL-KADI, S.W.; SUNNY, N.E.; OBA, M. et al. Glucose metabolism by the gastrointestinal tract of sheep as affected by protein supply. In. SOUfFrant, W.B.; METGES, C.C. (Eds.) Progress in research on energy and protein metabolism Wageningen: Academic Publishers, 2003.p.401-404 (EAAP Scientific Series, 109).

GOETSCH, A.L. Splanchnic tissue energy use in ruminants that consume forage-based diets ad libitum. Journal of Animal Science, v.76, p.2737-2746, 1998.

GOETSCH, A.L.; PATIL, A.R.; GALLOWAY, D.L. et al. Net flux of nutrients across splanchnic tissues in wethers consuming grasses of different sources and physical forms ad libitum. British Journal of Nutrition, v.77, p.769-781, 1997.

HUNTINGTON, G.B. Portal blood flow and net absorption of ammonia-nitrogen, urea-nitrogen, and glucose in nonlactating holstein cows. Journal of Dairy Science, v.65, 1155-1162, 1982.

HUNTINGTON, G.B. Sources of variation in splanchnic blood flow in steers. Journal of Animal Science, v.77, p.3031-3036, 1999.

HUNTINGTON, G.B.; REYNOLDS, C.K. Oxygen consumption and metabolite flux of bovine portal-drained viscera and liver. Journal of Nutrition, v.117, p.1167-1173, 1987.

KATZ, M.L.; BERGMAN, E.N. Simultaneous measurements of hepatic and portal venous blood flow in the sheep and dog. American Journal of Physiology, v.216, p.946-952, 1969. KOMAREK, A.R. A filter bag procedure for improved efficiency of fiber analysis. Journal of Dairy Science, v.76, p.250, 1993 (suppl.1) 
KOZLOSKI, G.V.; PEROTONI, J.; CIOCCA, M.L.S. et al. Potential nutritional assessment of dwarf elephant grass (Pennisetum purpureum Schum. Mott) by chemical composition, digestion and net portal flux of oxygen in cattle. Animal Feed Science and Technology, v.104, p.29-40, 2003.

KOZLOSKI, G.V.; LIMA, L.D.; FIORENTINI, G. et al. Implantação e avaliação do método de multicateterização em ovinos. Ciência Rural, v.38, p.258-261, 2008.

LIMA, L.D. Potencial nutricional do feno de capim arroz (Echicochloa sp.) através da caracterização química, da digestão e do fluxo visceral líquido de oxigênio em ovinos. 2007. 90f. Dissertação (Mestrado em Zootecnia) - Universidade Federal de Santa Maria, Santa Maria, 2007.

MCBRIDE, B.W.; KELLY, J.M. Energy cost of absorption and metabolism in the ruminant portal-drained viscera and liver: a review. Journal of Animal Science, v.68, p.2997-3010, 1990.

MERTENS, D.R. Gravimetric determination of amylase-treated neutral detergent fibre in feeds with refluxing beakers or crucibles: a collaborative study. Journal of AOAC, v.85, p.1217-1240, 2002.

MILANO, G.D.; MOORE, H.; LOBLEY, G.E. Influence of hepatic ammonia removal on ureagenesis, amino acid utilization and energy metabolism in the ovine liver. British Journal of Nutrition, v.83, p.307-315, 2000.

MOURO, G.F.; BRANCO, A.F.; HARMON, D.L. et al. Fontes de carboidratos e ionóforo em dietas contendo óleo vegetal para ovinos: digestibilidade, balanço de nitrogênio e fluxo portal de nutrientes. Revista Brasileira de Zootecnia, v.35, p.2144-2153, 2006.
MOURO, G.F.; BRANCO, A.F.; HARMON, D.L. et al. Fontes de carboidratos e porcentagem de volumosos em dietas para ovinos: balanço de nitrogênio, digestibilidade e fluxo portal de nutrientes. Revista Brasileira de Zootecnia, v.36, p.489-498, 2007.

NELSON, C.J.; MOSER, L.E. Plant factors affecting forage quality. In: FAHEY JR., G.C. (Ed.). Forage quality, evaluation, and utilization. Madison: ASA, CSSA, SSSA, 1994. p.115-154.

PALMER, D.W.; PETERS JR., T. Automated determination of free amino groups in serum and plasma using 2,4,6 trinitro-benzene sulfonate. Clinical Chemistry, v.15, p.891-901, 1969.

ORTIGUES, I.; DURAND, D.; LEFAIVRE, J. Use of para-amino hippuric acid to measure blood flows through portal-drainedviscera, liver and hindquarters in sheep. Journal of Agricultural Science, v.122, p.299-308, 1994.

REYNOLDS, C.K.; TYRREL, H.F.; REYNOLDS, P.J. Effects of diet forage-to-concentrate ratio and intake on energy metabolism in growing beef heifers: Whole body energy and nitrogen balance and visceral heat production. Journal of Nutrition, v.121, p.994-1003, 1991.

SOLE, M.J.; RECAVARREN, M.I.; MILANO, G.D. Splanchnic energy expenditure and net nutrient flux in sheep fed diets with varying concentrate:forage ratios. Journal of Animal and Feed Sciences, v.13, p.307-310, 2004 (supp1. 1).

STATISCAL ANALYSIS SYSTEM - SAS. SAS/STAT ${ }^{\circledR}$ User's guide. Version 9.1. Cary: SAS Institute, 2004. 5136p.

WEATHERBURN, M.W. Phenol-hypochlorite reaction for determination of ammonia. Analytical Chemistry, v.39, p.971-974, 1967. 